OPEN ACCESS

Edited by:

Xiaogan Li

Dalian University of Technology

(DUT), China

Reviewed by:

Azhar Ali Haidry,

Nanjing University of Aeronautics and

Astronautics, China

Zhenyu Li,

Southwest Petroleum

University, China

*Correspondence:

Jianxin $Y_{i}$

yjx@ustc.edu.cn

Specialty section:

This article was submitted to

Functional Ceramics,

a section of the journal

Frontiers in Materials

Received: 21 May 2019 Accepted: 19 September 2019

Published: 04 October 2019

Citation:

Han J, Chen W, Yu A and Yi J (2019) Detection of Semi-volatile Plasticizers as a Signature of Early Electrical Fire.

Front. Mater. 6:250

doi: $10.3389 /$ fmats.2019.00250

\section{Detection of Semi-volatile Plasticizers as a Signature of Early Electrical Fire}

\author{
Jia Han, Wenjia Chen, Aihua Yu and Jianxin Yi* \\ State Key Laboratory of Fire Science, Department of Safety Science and Engineering, University of Science and Technology \\ of China, Hefei, China
}

Detection of characteristic species released from over-heated PVC cables may enable early warning of electrical fire. This work identified the major volatile species for over-heated PVC cables, and verified their potential as fire signatures with metal oxide gas sensors. Semi-volatile Dioctyl phthalate (DOP) and 2-Ethylhexanol (2-EH) were found to be ubiquitously present in the cable vapors as major species. Detection of these species and the vapors of overheated cables was accomplished with a metal oxide gas sensor. The response of the gas sensor to the cable vapors resulted mainly from DOP and 2-EH, demonstrating them as effective signature gases for over-heated PVC cables. A gas sensor based on $\mathrm{SnO}_{2}$ nanofibers was prepared with greatly enhanced response to the signature gases. Large-scale simulation tests showed that the nanofiber gas sensor could effectively detect the cable overheating at an early stage.

Keywords: gas sensor, detection, electrical fire, plasticizer, semi-volatile

\section{INTRODUCTION}

Fire cause severe property damages and casualties in modern society. A key to successful fire prevention and controlling is the accurate detection of fire characteristics as early as possible. The fire characteristics can vary greatly for various types and at different stages of fires (Fonollosa et al., 2018). So far numerous fire detectors based on the detection of gas, smoke, temperature, flame, etc., have been developed (Han and Lee, 2009; Verstockt et al., 2010). Gases or chemical vapors due to pyrolysis or smoldering of the combustible materials are usually emitted before the other fire characteristics become evident, such as smoke and temperature change, and could thus be used as a signature of fire (Fonollosa et al., 2018; Vincent et al., 2019). For many conventional fires, CO has been recognized as the signature gas, which has led to successful application of $\mathrm{CO}$ gas sensors in commercial fire detectors. However, $\mathrm{CO}$ sensors are not suitable for detection of electrical fire at the early stage as little CO may be emitted then (Beneš et al., 2004; Li, 2014; Chen and Yi, 2019).

Electrical cables with insulation and/or sheath based on PVC (polyvinyl chloride) materials are currently widely used in residential and industrial applications. The PVC insulation/sheath starts to degrade significantly or ignite at a temperature above $\sim 200-240^{\circ} \mathrm{C}$, outgassing $\mathrm{HCl}, \mathrm{CO}, \mathrm{CO}_{2}$, etc. (Beneš et al., 2004; Li, 2014; Courty and Garo, 2017; Wang et al., 2018; Chen and Yi, 2019). Typically the PVC used for cables contains a large amount of various additives in the polymeric PVC matrix, such as plasticizers, stabilizers, inorganic fillers, and antioxidants (Linde and Gedde, 2014). Plasticizers such as DOP are semi-volatile organic compounds (SVOC) with low saturation vapor pressures at normal cable operation temperatures $\left(70-90^{\circ} \mathrm{C}\right)$. At higher temperatures where cable is overheated, release of these volatile species could become substantial due to the increased vapor 
pressure and large abundance in the cable insulation $(\mathrm{Li}, 2014$; Chen and Yi, 2019). In particular, they may accumulate in confined/closed spaces, such as cabinets for electric power distribution or control, electrical apparatuses, and appliances. Detection of the major species therein may allow warning of malfunctioned cables and early stage of fires.

Recent studies showed that metal oxide semiconductor (MOS) gas sensors could respond to the emitted vapors of overheated or pyrolyzed PVC cables (Zhao et al., 2014; Knoblauch et al., 2015; Lee et al., 2017; Chen and Yi, 2019). Unfortunately, the compositions of these vapors, which are rather complex and could vary greatly with the type, composition of the cable and heating conditions (temperature and duration), etc., have not yet been determined. So far, it is still uncertain what species are predominantly and ubiquitously present in the vapors for different cables, and their quantitative concentrations as a function of temperature. Moreover, the response characteristics of MOS sensors to these major species remain also unknown. Knowledge about these will not only enable identification of the signature gases for early detection of electrical fires, but also provide a vital guideline for the selection and development of gas sensors specifically targeting these gases.

In this study, vapor compositions for different overheated PVC cables were systematically examined. Semi-volatile plasticizers were assessed as the signature gases of early-stage PVC cable fires. A TGS 822 gas sensor was responsive to the signature gases, but the response values were rather low. Considering that semiconductor-typed gas sensors based on nanostructured $\mathrm{SnO}_{2}$ are often effective for detection of VOCs (Srivastava, 2003; Upadhyay, 2013; Knoblauch et al., 2015; Kou et al., 2016; Jiang et al., 2017), we prepared a $\mathrm{SnO}_{2}$ nanofiber gas sensor for detection of the plasticizers. The sensor showed significantly enhanced response to the signature gases, and could detect the hazard due to the cable overheating.

\section{EXPERIMENTAL}

\section{Analysis of Vapor Composition}

Nine different commercial PVC cables of various model types from several different domestic manufacturers listed in Table 1 were studied in this work. Cables 1-8 are single-cored while cable 9 is two-cored. The maximum continuous operation temperature is $70^{\circ} \mathrm{C}$ for all the cables. The PVC insulation of the cables was stripped from the cables and cut into a length of $2 \mathrm{~mm}$ per piece. The samples were ultrasonically cleaned successively in water and ethanol, which procedures were repeated for several times.
To analyze the vapor composition, gas chromatographymass spectrometry (GC-MS) was conducted on an Agilent $6890 \mathrm{~N} / 5973$ system equipped with a headspace injector (G1888, Agilent). 0.5-2.0 g PVC insulation sample was hermetically sealed in a $20 \mathrm{ml}$ headspace bottle and heated by the headspace injector. The temperature of the GC column (HP-5MS) was programmed as follows: held at $60^{\circ} \mathrm{C}$ for $1 \mathrm{~min}$, and ramped to $220^{\circ} \mathrm{C}$ at $20^{\circ} \mathrm{C} / \mathrm{min}$, held for $1 \mathrm{~min}$, and subsequently ramped to $280^{\circ} \mathrm{C}$ at $5^{\circ} \mathrm{C} / \mathrm{min}$, held for $4 \mathrm{~min}$. Helium (99.999\%) was used as the carrier gas of the GC.

Variation of vapor compositions with heating time and sample mass was examined. To attain reasonable experimental accuracy and high efficiency, the vapors obtained by heating $1 \mathrm{~g}$ sample for $30 \mathrm{~min}$ is used for the identification of GC-MS, which could allow the major components in the vapors to reach saturation (Supplementary Figure 1). In some experiments, in order to examine variation of the concentration of the major vapor components with the pre-heating time, the PVC samples were subjected to pre-heating for a certain period in open air prior to being sealed in the headspace bottles. Note that as a large tailing peak appeared at the beginning of the GC-MS spectra due to the ambient air contained in the headspace bottles, the GC-MS data acquisition began from the retention time of $3 \mathrm{~min}$.

Dioctyl phthalate (purity $>99.5 \%$ ) and 2-Ethylhexanol (purity $>99.6 \%$ ) purchased from SIGMA-ALDRICH were used as standards for the GC-MS measurements and sensor tests. The concentration of DOP and 2-EH in the vapors released from the cable insulation was quantified by external standard calibration. To obtain the calibration plots (Supplementary Figure 2), $1 \mu$ of the standard solutions containing various concentrations of DOP and 2-EH in ethanol was injected to the GC-MS.

\section{Gas Sensor Preparation and Tests}

Gas sensing measurements were conducted with a TGS-822 MOS gas sensor (Figaro, Japan) and home-made gas sensor based on $\mathrm{SnO}_{2}$ nanofibers. The $\mathrm{SnO}_{2}$ nanofibers were synthesized via electrospinning followed by calcination at $600^{\circ} \mathrm{C}$ for $3 \mathrm{~h}$. Details of the materials preparation and characterization using X-ray diffraction (XRD), scanning electron microscope (SEM), transmission electron microscopy (TEM), and X-ray photoelectron spectroscopy (XPS) can be found in Yi et al. (2018). To prepare the gas sensor, the nanofibers were dispersed in ethanol, and the obtained paste was coated onto an alumina tube with two gold electrodes and platinum wires. The coated tube was then calcined at $400^{\circ} \mathrm{C}$ for $2 \mathrm{~h}$. The width of the electrodes and the gap between them were around $1 \mathrm{~mm}$. A Ni-Cr wire was inserted

TABLE 1 | Specification of the cables used in this study.

\begin{tabular}{|c|c|c|c|c|c|c|c|c|c|}
\hline Cable no. & 1 & 2 & 3 & 4 & 5 & 6 & 7 & 8 & 9 \\
\hline Company & Yuandong & Yuandong & Delixi & Feidiao & Lvbao & Lvbao & Zhengtai & Xiongmao & Xiongmao \\
\hline Type & BV 2.5 & BV 4.0 & BV 2.5 & BV 2.5 & BV 2.5 & BV 4.0 & BV 4.0 & BVR2.5 & $\mathrm{RW} 22^{* 1}$ \\
\hline Sectional Area of conductor $\left(\mathrm{mm}^{2}\right)$ & 2.5 & 4.0 & 2.5 & 2.5 & 2.5 & 4.0 & 4.0 & 2.5 & 1 \\
\hline Insulation thickness (mm) & 0.8 & 0.8 & 0.8 & 0.8 & 0.8 & 0.8 & 0.8 & 0.8 & 0.6 \\
\hline
\end{tabular}

Maximum continuous operation temperature of the cables is $70^{\circ} \mathrm{C}$. 
A

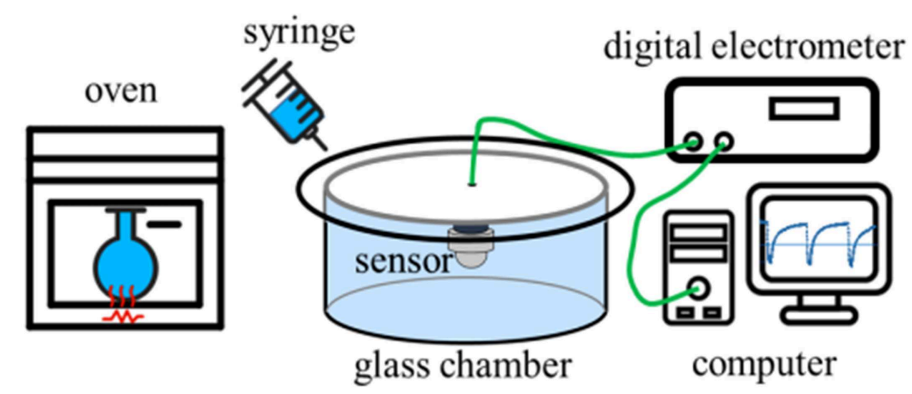

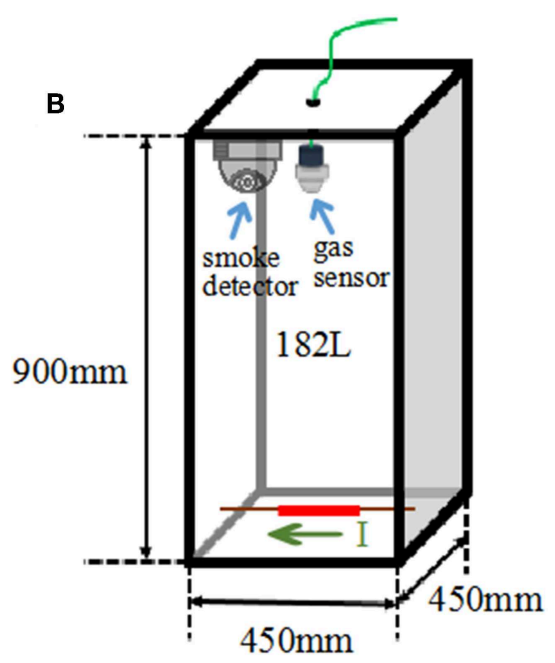

FIGURE 1 | Schematic diagrams of sensor tests. (A) Bench-scale test, (B) large-scale simulation test.

through the core of the alumina tube as the heater of the sensor.

Bench-scale gas sensing measurements were conducted in a $480 \mathrm{ml}$ glass chamber to evaluate the response characteristics of the gas sensor using a static air testing method similar to that described in Li and Yi (2017) and Chen and Yi (2018). The gas sensor was first allowed to reach steady state in ambient air (Figure 1A). Sample vapors of desired concentration were injected with a syringe injector into the test chamber to result in changes in the sensor resistance. The sensor was removed from the glass chamber and exposed in ambient air to recover the resistance after the test. Vapors of DOP, 2-EH, and their mixtures were obtained by evaporating appropriate amounts of the respective liquids in a glass reagent bottle at $150-200^{\circ} \mathrm{C}$. Vapors of cable insulation were obtained through a method similar to that used in the GC-MS measurements. Resistance of the sensor was measured by a digital electrometer (Agilent, 34972A). The sensor response is defined as $S=R_{a} / R_{g}$, where $R_{a}$ and $R_{g}$ are the resistance of the sensor in ambient air and target gas, respectively. Humidity of the ambient air was measured with a hygrometer, which varied in the range of $48-54 \%$ in this study.

Large scale sensor tests were also conducted in a $45 \mathrm{~cm} \times$ $45 \mathrm{~cm} \times 90 \mathrm{~cm}$ acrylic chamber of $182 \mathrm{~L}$ volume (Figure 1B), in order to simulate the actual scenario that cables become overheated under load in confined spaces. A piece of $11 \mathrm{~cm}$ long cable insulation $(1.0 \mathrm{~g})$ was placed at the bottom center of the chamber. A Ni/Cr heating wire running through the cable core was used to control the cable temperature by adjusting the electric current passing it. A thermocouple was tightly attached to heating wire to monitor the actual temperature. The cable insulation was heated from room temperature to and dwelled at a target temperature. The gas sensors were located at the upper center of the chamber to monitor the gas release. For comparison, a Honeywell photoelectric smoke detector (JTYJ-GD-01LM/BW) was also installed adjacent to the gas sensors.

\section{RESULTS AND DISCUSSION}

GC-MS analyses for 9 different cables under overheating conditions showed that the vapors released consisted of various organic compounds of high boiling points (Figure 2 and Table 2). Although the compositions varied significantly with the type of cables and temperature, it can be distinctly seen that DOP and 2-EH, two widely used plasticizers, were present as common and most abundant species in all cable vapors. The quantified saturation concentrations of DOP and 2-EH in the vapors increased with increasing temperature (Figure 3). The evident release of DOP began since a cable temperature of $130^{\circ} \mathrm{C}$ with a saturated concentration of $\sim 10-30 \mathrm{ppm}$, which climbed to 550 $2,000 \mathrm{ppm}$ at $200^{\circ} \mathrm{C}$. With regard to $2-\mathrm{EH}$, the concentration was higher for most cables, and evident release began for some cables already at a temperature as low as $70^{\circ} \mathrm{C}$. The concentrations of both DOP and 2-EH can be maintained at these high values, even after the cable was subject to prolonged pre-heating in open air at $150^{\circ} \mathrm{C}$ for up to $12 \mathrm{~h}$ (Supplementary Figure 3), indicating that their release are sustainable under the given conditions. Note that significant presence of 2-EH under similar conditions was not detected by pyrolysis GC-MS or TG-IR measurements in previous reports (Li, 2014; Chen and Yi, 2019), which can be ascribed to the too low concentration of 2-EH therein. In those measurements only a small amount (up to several tens of mg) of PVC sample was used, and the carrier gases further diluted the vapors generated. In contrast, a much larger sample mass $(1 \mathrm{~g})$ was used and the 2-EH was enriched in the sealed headspace bottle in this work. The results obtained herein suggest that both DOP and 2-EH hold promise as candidates of a universal signature gas of early cable fires.

A fire signature must be able to be reliably detected for warning of fires. Currently, no commercial gas sensor that is known to be specifically sensitive to DOP and 2-EH is available. As a result, a TGS822 MOS gas sensor, which is designated for sensing VOC gases, was used to assess the 

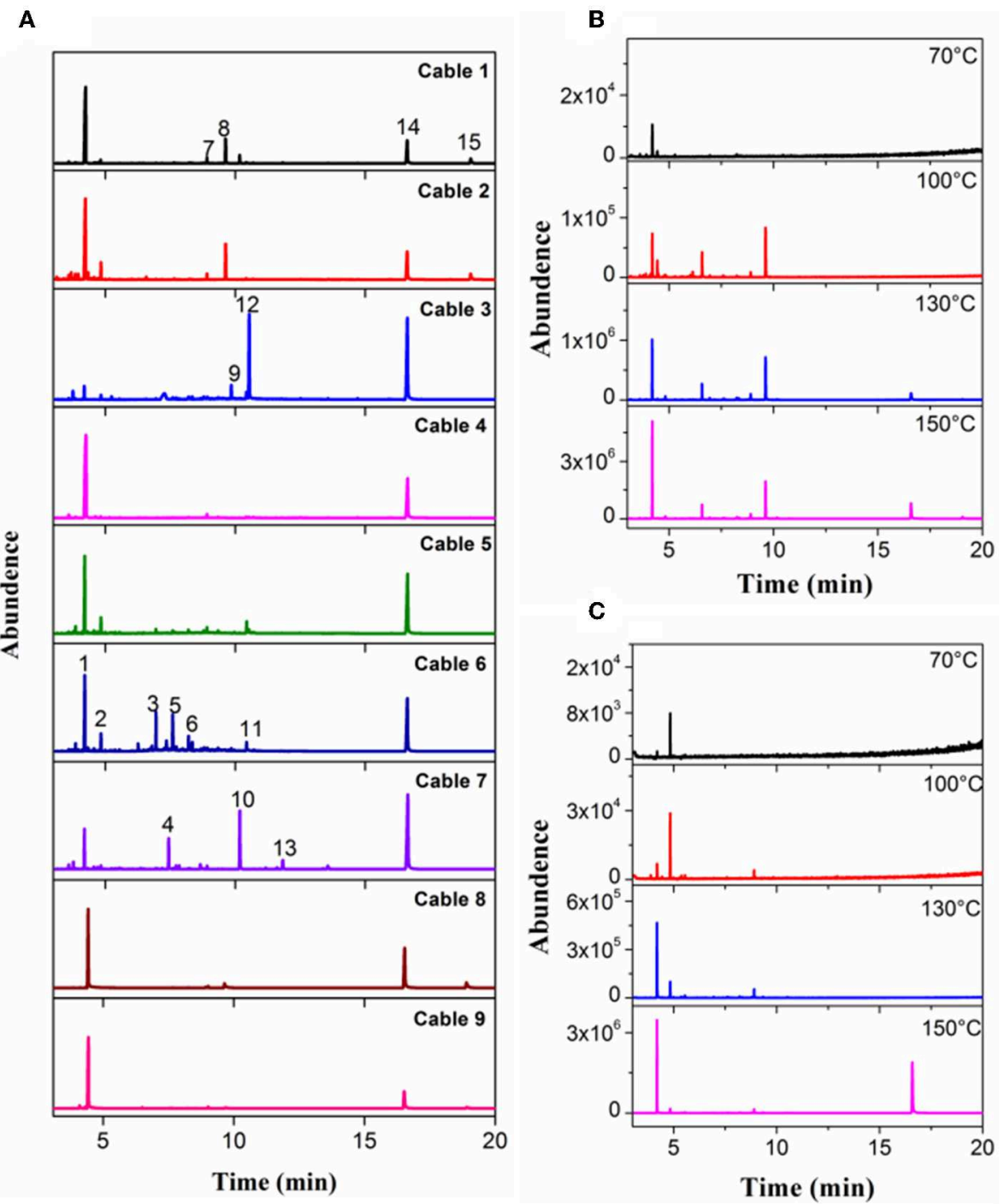

FIGURE 2 | Chromatograms measured with headspace GC-MS for (A) Cable 1-9 at 200 ${ }^{\circ}$, (B) Cable 1, and (C) Cable 4 at selected temperatures.

validity of using DOP and 2-EH as the signature gases of electrical fires. Bench-scale gas sensing measurements were performed in a $480 \mathrm{ml}$ chamber. As shown in Figure 4A, the resistance of the TGS sensor decreased rapidly in the presence of DOP and 2-EH. When the signature gases were removed, the sensor resistance restored gradually back to the initial values. The resistance change, i.e., the sensor response, was found to vary greatly for DOP on the heating voltage and hence the temperature of the sensor. A typical volcano-shaped dependence was observed, with a maximum response of 8.6 for $100 \mathrm{ppm}$ DOP at $4.1 \mathrm{~V}$ (Figure 4B). In contrast, the sensor response to 2$\mathrm{EH}$ exhibited much weaker temperature dependence, and varied only slightly within 2.5-3.2. Based on these results, the heater voltage was set at $4.1 \mathrm{~V}$ for this sensor where optimized sensor performance can be achieved for both DOP and 2-EH in the following measurements.
Figure 5 compares the sensor response to the cable vapors with that to the simulated vapors. The simulated vapors were obtained by heating and vaporizing a mixture of DOP and 2-EH standards, wherein the concentration of DOP and 2$\mathrm{EH}$ was kept, respectively, equal to that in the cable vapors according to Figure 3. The gas concentration in the sensor testing chamber was adjusted by varying the sampling volume of the vapors or the heating temperature of the cables/standards. As a representative, cable 1 and cable 4 were tested. It can be seen that for the cable vapors, the sensor response increased monotonically with either the sampling volume or heating temperature, i.e., with increase of the gas concentration. Furthermore, the sensor response for the cable vapors matched very closely with that for the simulated vapors in all cases. These results have two important implications. The first is that the response of the gas sensor to the cable vapors contributes 
TABLE 2 | Compositions of cable 1-9 determined by the headspace GC-MS at a sample temperature of $200^{\circ} \mathrm{C}$.

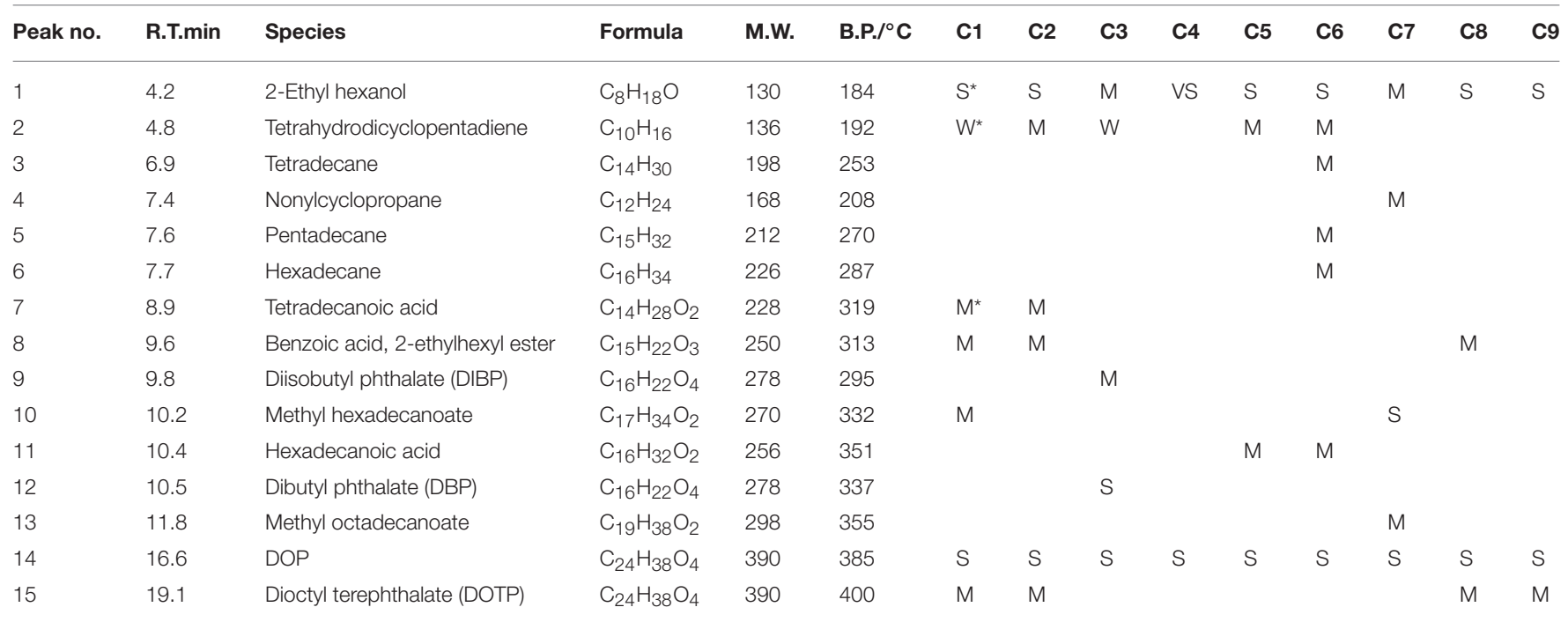

${ }^{*} V S, S, M$, and $W$ denote very strong, strong, medium, and weak, respectively. They correspond to an area of the chromatographic peak of $>10^{9}, 10^{8} \sim 10^{9}, 10^{7} \sim 10^{8}$, and $<10^{7}$, respectively.
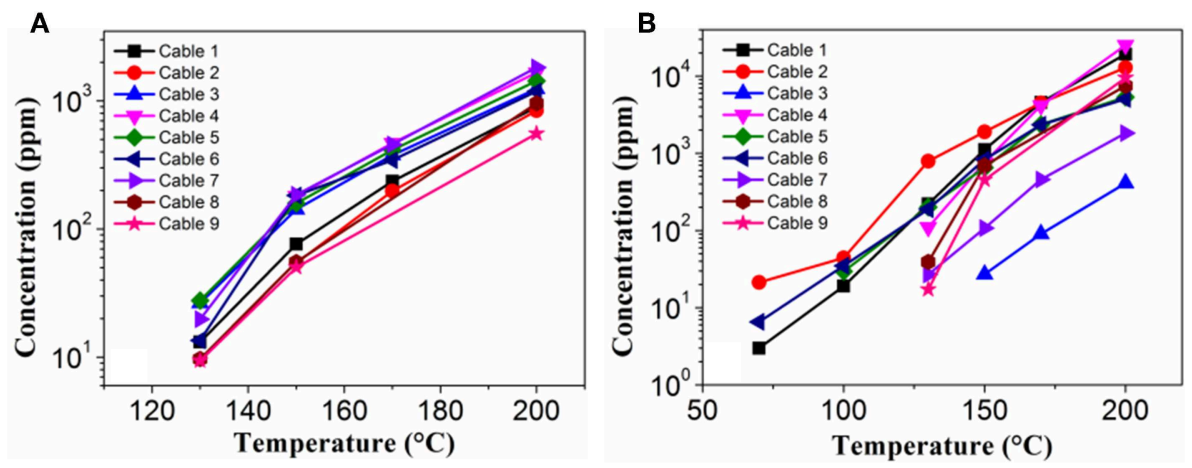

FIGURE 3 | Calibrated concentration of (A) DOP and (B) 2-EH at different cable temperatures.
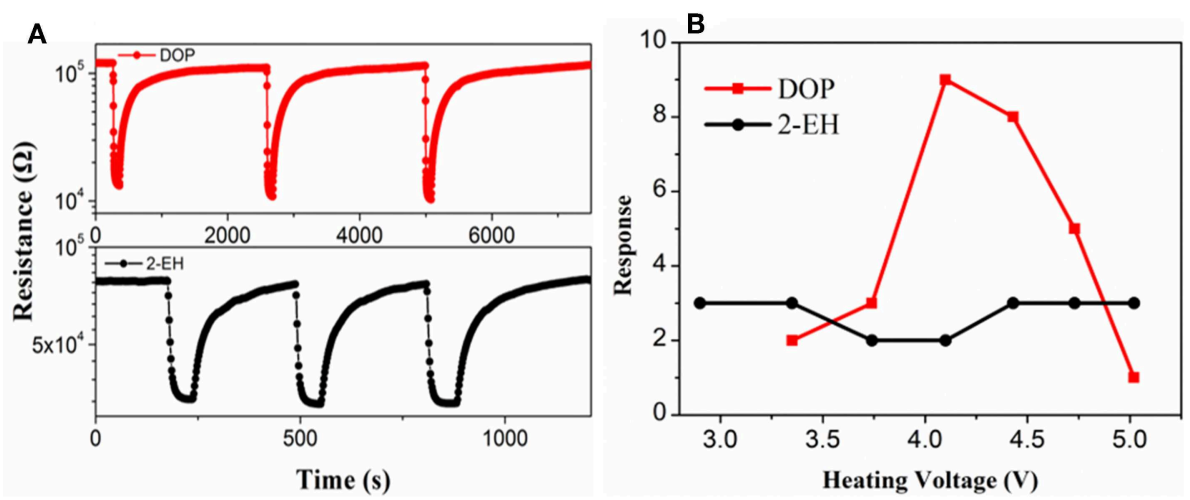

FIGURE 4 | (A) Response transients and (B) response values of the TGS-822 sensor to 100 ppm vapors of DOP and 2-EH standards. 
primarily from that to DOP and 2-EH, since both DOP and 2 -EH are dominant species in the cable vapors. Note that for cable 1, some additional compounds were present in the obtained vapors (Table 2), which did not seem to interfere significantly the sensor response. The second is that change of the cable temperature can be detected by monitoring the concentration variation of DOP and 2-EH with gas detectors. These results clearly demonstrate that early warning of electrical fires is feasible through detection of DOP and 2-EH with MOS gas sensors.

Although the TGS-822 sensor was able to respond to the signature gases, the response value was very limited especially for 2-EH (Figure 4B). High sensing response to the signature gases is crucial for reliable and timely detection of cable over-heating in practical large-scale scenarios and at low cable temperatures, where the concentrations of the gases will be very low. Improved performance could in principle be achieved by using gas sensors based on nanostructured materials (Kim et al., 2013). As a demonstration, a gas sensor based on electrospun $\mathrm{SnO}_{2}$ nanofibers was prepared. The $\mathrm{SnO}_{2}$ nanofibers exhibited a single-phase tetragonal rutile structure. They were found to be porous and hollow, assembled by particles of several tens of nanometers. The diameter was $\sim 120 \mathrm{~nm}$ and the length varied typically in the range of $0.5-$ $2 \mu \mathrm{m}$. More details about the phase composition, morphology, and chemical states of the nanofibers can be found in Yi et al. (2018). This work was instead focused on the gas sensing performance of the sensor based on these nanofibers. Similar to the TGS-822, the nanofiber sensor also exhibited resistance reduction when exposed to the reducing gases of DOP and 2-EH, suggesting n-type semiconductor mechanism. Following this mechanism, the reducing gas reacts with the oxygen anion adsorbed on the surface of the semiconductor, resulting in a decrease of the resistance (Haidry et al., 2018). As shown in Figure 6, the maximum response reached 41 and 26 for $100 \mathrm{ppm}$ DOP and 2-EH, respectively, much larger than those for the TGS sensor (Yi et al., 2019). Note

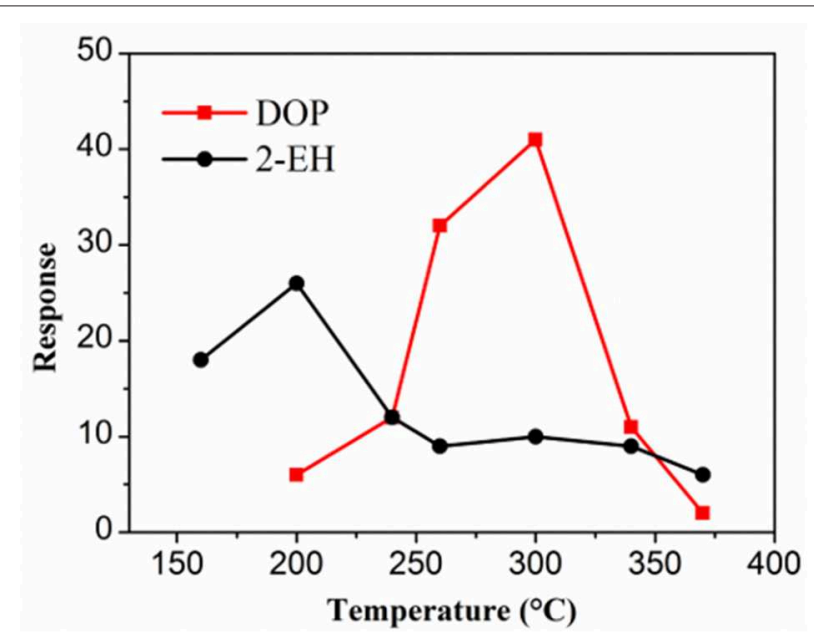

FIGURE 6 | Response of $\mathrm{SnO}_{2}$ nanofiber sensor to 100 ppm vapors of DOP and 2-EH standards.
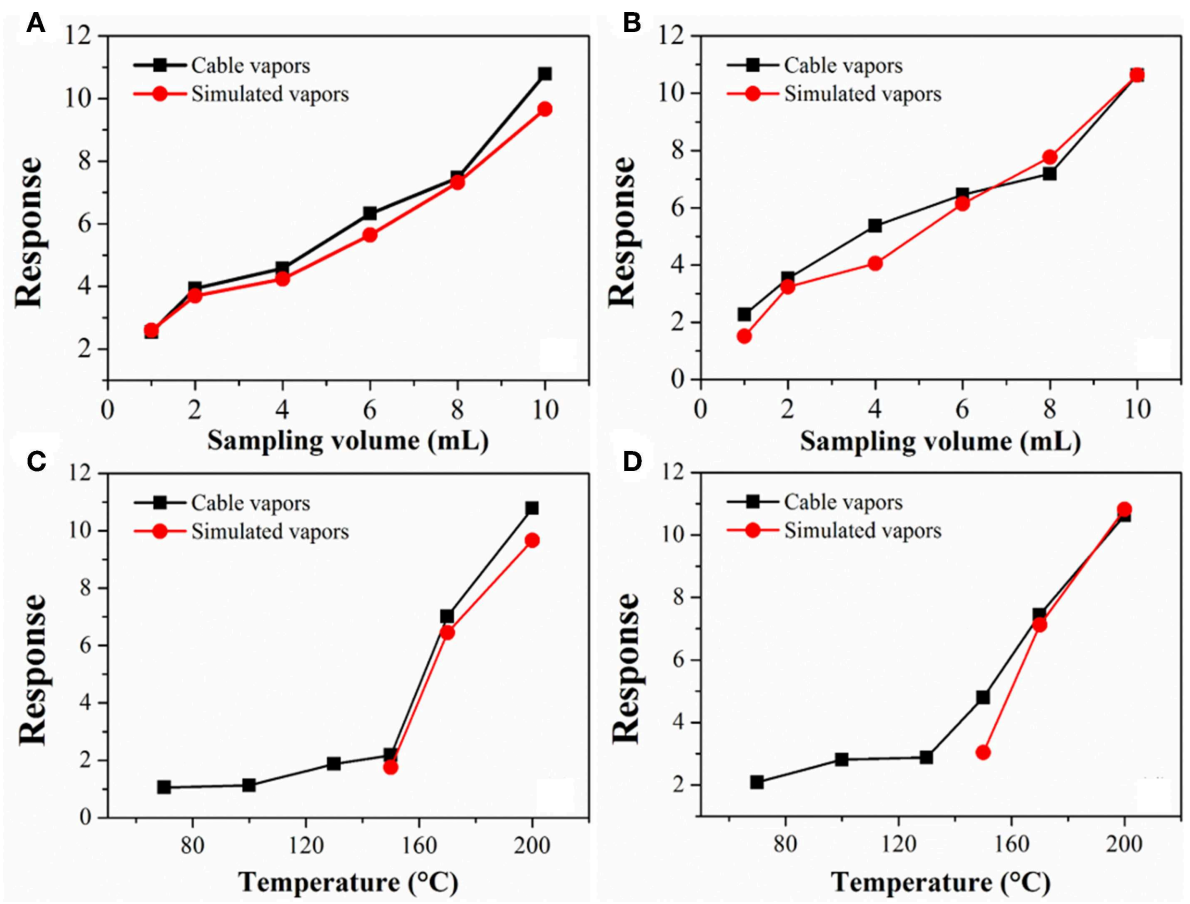

FIGURE 5 | Response variation of TGS-822 sensor with (A,B) the sampling volume and (C,D) temperature for vapors of $(\mathbf{A}, \mathbf{C})$ cable 1 and $\mathbf{( B , D )}$ cable 4 . For comparison, data for simulated vapors consisting of only DOP and 2-EH standards are also presented. 

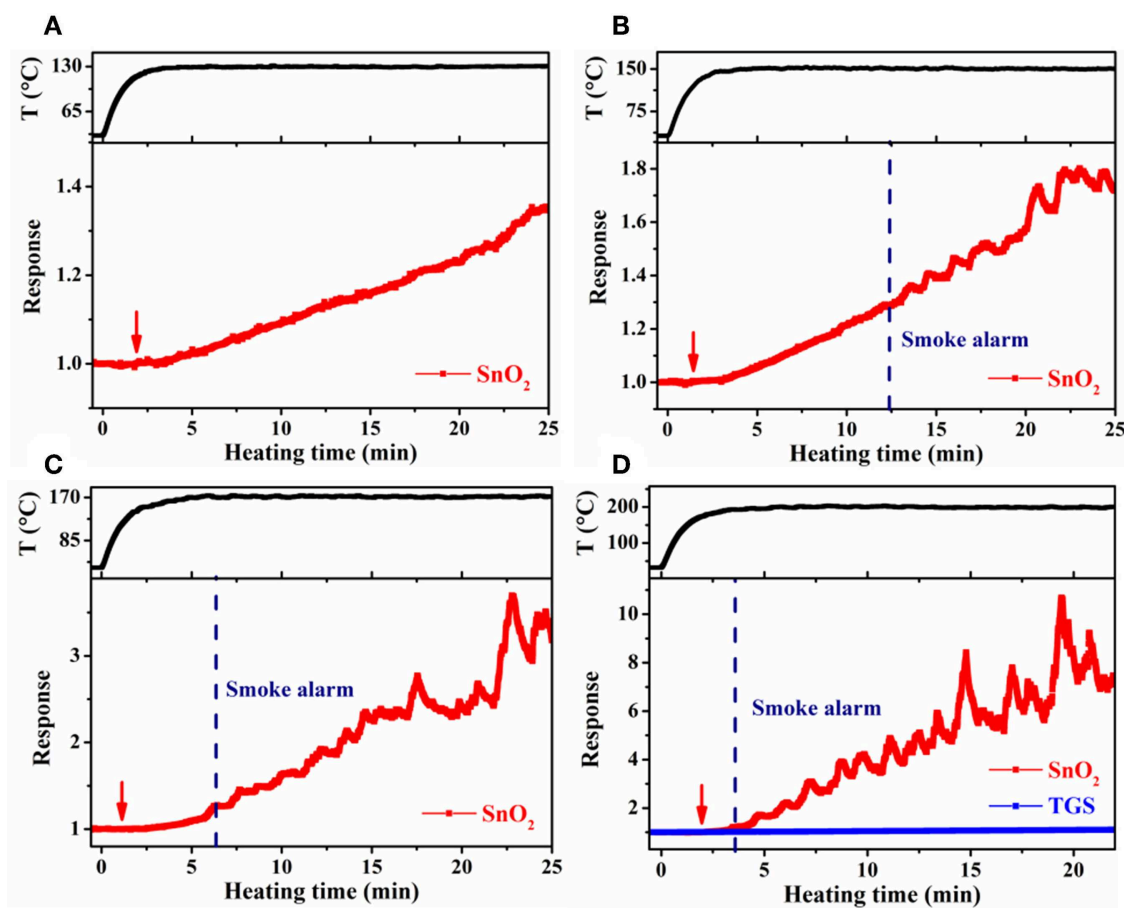

FIGURE 7 | Response of $\mathrm{SnO}_{2}$ nanofiber sensor as a function of heating time at a cable temperature of (A) $130^{\circ} \mathrm{C}$, (B) $150^{\circ} \mathrm{C},(\mathbf{C}) 170^{\circ} \mathrm{C}$, and (D) $200^{\circ} \mathrm{C}$ during large-scale simulation tests for cable 1. Arrow indicate onset of sensor response.
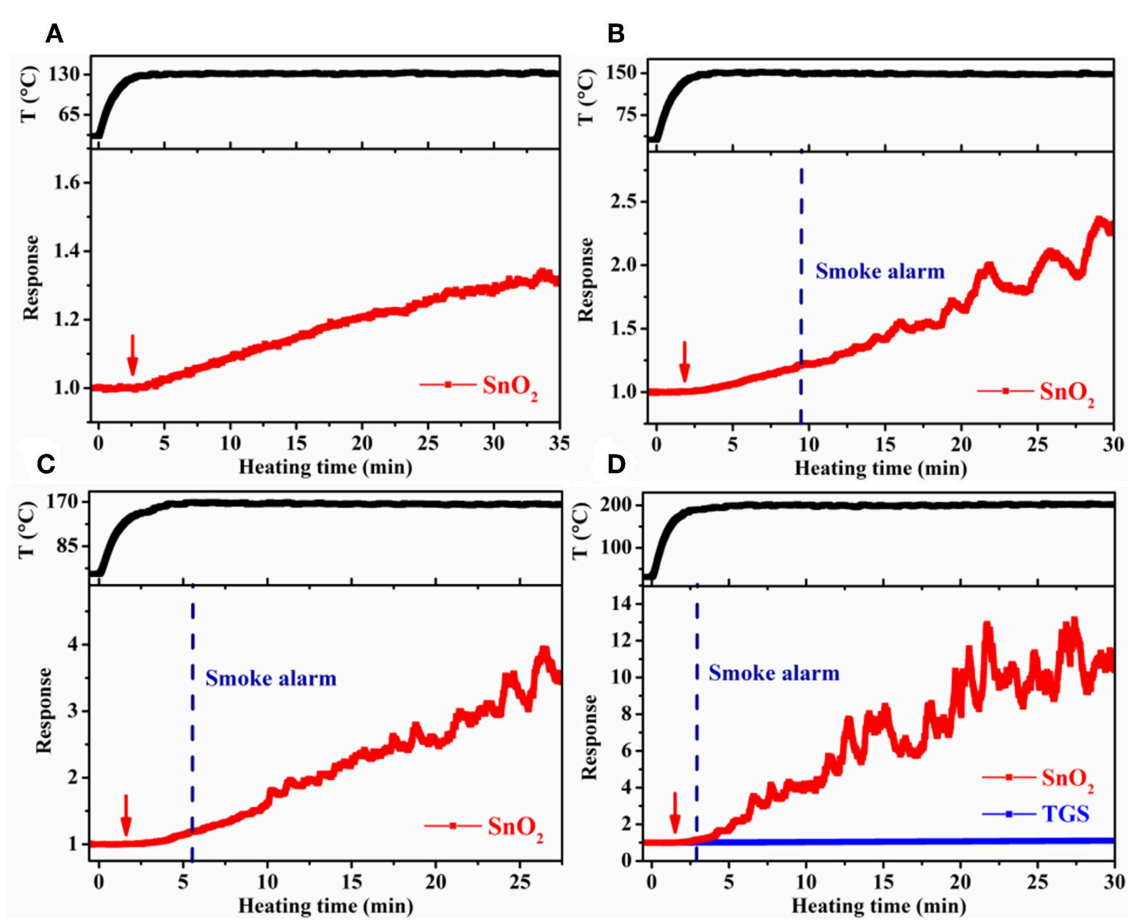

FIGURE 8 | Response of $\mathrm{SnO}_{2}$ nanofiber sensor as a function of heating time at a cable temperature of (A) $130^{\circ} \mathrm{C},(\mathbf{B}) 150^{\circ} \mathrm{C},(\mathbf{C}) 170^{\circ} \mathrm{C}$, and (D) $200^{\circ} \mathrm{C}$ during large-scale simulation tests for cable 4. 
that the optimal temperature of $\mathrm{SnO}_{2}$ nanofiber for sensing DOP $\left(300^{\circ} \mathrm{C}\right)$ and $2-\mathrm{EH}\left(200^{\circ} \mathrm{C}\right)$ was very different, thus the sensor temperature was set at $260^{\circ} \mathrm{C}$ as a compromise in the following tests. Note also that other experimental conditions, such as electrode structure and dimension, may also affect the sensor performance (Langer et al., 2015; Haidry et al., 2016, 2019; Sun et al., 2018; Fatima et al., 2019), which deserves further investigation.

Large-scale simulation sensor tests were performed in a $182 \mathrm{~L}$ acrylic chamber, wherein the temperature of the cable insulation was controlled through adjusting the electric current passing the heater in the cable core. In such a way, the conditions resembled the actual scenario that cables become overheated under load in confined spaces, such as power distribution cabinets and electrical appliances. To obtain higher target cable temperatures, a larger heating current had to be used. As a result, the heating time to reach $70^{\circ} \mathrm{C}$ (the maximum continuous working temperature of the PVC cables used) slightly decreased from 0.5 to $0.3 \mathrm{~min}$, as the target cable temperature increased from $130^{\circ}$ to $200^{\circ} \mathrm{C}$. Despite this difference, it took $\sim 5 \mathrm{~min}$ in each case for the cable temperature to reach steady at the target temperature. Cable 1 and 4 were tested, and the results were presented in Figures 7, 8. For the target temperature of $130^{\circ} \mathrm{C}$ (Figure 7A), response of the $\mathrm{SnO}_{2}$ nanofiber gas sensor started distinctly at $\sim 3.3 \mathrm{~min}$ (referred to as gas alarm time hereafter), and the value continuously increased with time. The increase of response with time is consistent with the more pronounced emission of the signature gases at higher temperatures in Figure 3. In contrast to the gas sensor response, no alarm was triggered for the smoke detector. As the target temperature was raised, the gas alarm time slightly reduced to 3.0, 2.5, and $2.1 \mathrm{~min}$ (Figures 7B-D), for $150^{\circ}, 170^{\circ}$, and $200^{\circ} \mathrm{C}$, respectively. For these higher temperatures, the smoke alarm was triggered, but at a much later time than the gas alarm, i.e., at $12.4,6.4$, and $3.6 \mathrm{~min}$, respectively. For the case of cable 4 , similar phenomena were observed, where both the gas and smoke alarm time were slightly shorter (Figure 8). It is also important to note that during simulation tests, no significant response was observed for the TGS gas sensor (Figures 7D, 8D), consistent with its low response to the signature gases. These results reveal that gas sensors of high response to the signature gases, DOP and 2-EH, may be able to effectively detect the

\section{REFERENCES}

Beneš, M., Milanov, N., Matuschek, G., Kettrup, A., Plaček, V., and Balek, V. (2004). Thermal degradation of PVC cable insulation studied by simultaneous TG-FTIR and TG-EGA methods. J. Therm. Anal. Calorimetry 78, 621-630. doi: 10.1023/B:JTAN.0000046123.59857.ad

Chen, D., and Yi, J. (2018). One-pot electrospinning and gas-sensing properties of $\mathrm{LaMnO}_{3}$ perovskite/SnO $\mathrm{S}_{2}$ heterojunction nanofibers. J. Nanoparticle Res. 20:65. doi: 10.1007/s11051-018-4158-X

Chen, W., and Yi J. (2019). Identification and gas sensor testing of volatile signature gas for early detection of PVC cable fires. Fire Safety Sci. 28, 133-139. doi: 10.3969/j.issn.1004-5309.2019.02.04

Courty, L., and Garo, J. (2017). External heating of electrical cables and auto-ignition investigation. J. Hazard. Mater. 321, 528-536. doi: 10.1016/j.jhazmat.2016.09.042 overheating of PVC cables and thus enable early alarm of electrical fires.

\section{CONCLUSIONS}

The vapor compositions for nine different over-heated PVC cables were measured at various temperatures. Despite the varied compositions, two species of substantial abundance, DOP and 2-EH, were found ubiquitously present in the cable vapors. The concentration of both species in the vapors increased with temperature. Gas sensing measurements with a commercial TGS resistive gas sensor showed that these species can be effectively detected and could be used as fire signatures. $\mathrm{A} \mathrm{SnO}_{2}$ nanofiber gas sensor exhibited significantly enhanced response to the signature gases. The nanofiber sensor could detect the overheating of PVC cables and thus enable early alarm of electrical fires.

\section{DATA AVAILABILITY STATEMENT}

All datasets generated for this study are included in the manuscript/Supplementary Files.

\section{AUTHOR CONTRIBUTIONS}

JY designed the project. JH, WC, and AY conducted the experiments and analyzed the results. JY, JH, and WC wrote the manuscript.

\section{FUNDING}

This work was supported by the National Natural Science Foundation of China (grant No. 61871359) and fundamental research funds for the Central University (grant No. WK2320000044).

\section{SUPPLEMENTARY MATERIAL}

The Supplementary Material for this article can be found online at: https://www.frontiersin.org/articles/10.3389/fmats. 2019.00250/full\#supplementary-material

Fatima, Q., Haidry, A. A., Yao, Z., He, Y., and Xie, L. (2019). The critical role of hydroxyl groups on water vapor sensing of Graphene oxide. Nanoscale Adv. 1, 1319-1330. doi: 10.1039/C8NA $00135 \mathrm{~A}$

Fonollosa, J., Solórzano, A., and Marco, S. (2018). Chemical sensor systems and associated algorithms for fire detection: a review. Sensors 18:553. doi: $10.3390 / \mathrm{s} 18020553$

Haidry, A. A., Cetin, C., Kelm, K., and Saruhan, B. (2016). Sensing mechanism of low temperature $\mathrm{NO}_{2}$ sensing with top-bottom electrode (TBE) geometry. Sens. Actuat. B 236, 874-884. doi: 10.1016/j.snb.2016. 03.016

Haidry, A. A., Sun, L., Saruhan, B., Plecenik, A., Plecenik, T., Shen, H., et al. (2018). Cost-effective fabrication of polycrystalline $\mathrm{TiO}_{2}$ with tunable $\mathrm{n} / \mathrm{p}$ response for selective hydrogen monitoring. Sens. Actuat. B 274, 10-21. doi: 10.1016/j.snb.2018.07.082 
Haidry, A. A., Xie, L., Li, Z., Dong, B., Quwareer, F., and Wang, Z. (2019). Sol-gel synthesis of $\mathrm{TiO}_{2}$ with $\mathrm{p}$-type response to hydrogen gas at elevated temperature. Front. Mater. 6:96. doi: 10.3389/fmats.2019.00096

Han, D., and Lee, B. (2009). Flame and smoke detection method for early real-time detection of a tunnel fire. Fire Safety J. 44, 951-961. doi: 10.1016/j.firesaf.2009.05.007

Jiang, Z., Yin, M., and Wang, C. (2017). Facile synthesis of $\mathrm{Ca}^{2+} / \mathrm{Au}$ co-doped $\mathrm{SnO}_{2}$ nanofibers and their application in acetone sensor. Mater. Lett. 194, 209-212. doi: 10.1016/j.matlet.2017.02.031

Kim, I.-D., Rothschild, A., and Tuller, H. L. (2013). Advances and new directions in gas-sensing devices. Acta Mater. 61, 974-1000. doi: 10.1016/j.actamat.2012.10.041

Knoblauch, J., Illyaskutty, N., and Kohler, H. (2015). Early detection of fires in electrical installations by thermally modulated $\mathrm{SnO}_{2}$ /additive-multi sensor arrays. Sens. Actuat. B 217, 36-40. doi: 10.1016/j.snb.2015.02.014

Kou, X., Wang, C., Ding, M., Feng, C., Li, X., Ma, J., et al. (2016). Synthesis of Co-doped $\mathrm{SnO}_{2}$ nanofibers and their enhanced gas-sensing properties. Sens. Actuat. B 236, 425-432. doi: 10.1016/j.snb.2016.06.006

Langer, F., Perl, S., Höfling, S., and Kamp, M. (2015). p- to n-type conductivity transition in $1.0 \mathrm{eV}$ GaInNAs solar cells controlled by the V/III ratio. Appl. Phys. Lett. 106, 277-292. doi: 10.1063/1.4909507

Lee, K., Shim, Y.-S., Song, Y., Han, S., Lee, Y.-S., and Kang, C.-Y. (2017). Highly sensitive sensors based on metal-oxide nanocolumns for fire detection. Sensors 17:303. doi: $10.3390 / \mathrm{s} 17020303$

Li, N. (2014). Study on new electrical fire monitoring technology for low-voltage distribution cabinet. Build. Electricity 33:4. doi: 10.3969/j.issn.1003-8493.2014.07.007

$\mathrm{Li}, \mathrm{Z}$., and Yi, J. (2017). Enhanced ethanol sensing of Ni-doped $\mathrm{SnO}_{2}$ hollow spheres synthesized by a one-pot hydrothermal method. Sens. Actuat. B 243, 96-103. doi: 10.1016/j.snb.2016.11.136

Linde, E., and Gedde, U. W. (2014). Plasticizer migration from PVC cable insulation - The challenges of extrapolation methods. Polymer Degradation Stability 101, 24-31. doi: 10.1016/j.polymdegradstab.2014.01.021

Srivastava, A. (2003). Detection of volatile organic compounds (VOCs) using $\mathrm{SnO}_{2}$ gas-sensor array and artificial neural network. Sens. Actuat. B 96, 24-37. doi: 10.1016/S0925-4005(03)00477-5

Sun, L., Haidry, A. A., Fatima, Q., Li, Z., and Yao, Z. (2018). Improving the humidity sensing below $30 \% \mathrm{RH}$ of $\mathrm{TiO}_{2}$ with $\mathrm{GO}$ modification.
Mater. Res. Bull. 99, 124-131. doi: 10.1016/j.materresbull.2017. 11.001

Upadhyay, S. B. (2013). Volatile organic compounds (VOCs) response characteristics of the hydrothermally synthesized $\mathrm{SnO}_{2}$ nanocapsules. Sens. Lett. 11, 1-6. doi: 10.1166/sl.2013.3020

Verstockt, S., Vanoosthuyse, A., Hoecke, S. V., Lambert, P., and Walle, R. V. D. (2010). "Multi-sensor fire detection by fusing visual and non-visual flame features," in International Conference on Image \& Signal Processing (TroisRivières, QC). doi: 10.1007/978-3-642-13681-8_39

Vincent, T. A., Xing, Y., Cole, M., and Gardner, J. W. (2019). Investigation of response of high-bandwidth MOX sensors to gas plumes for application on a mobile robot in hazardous environments. Sens. Actuat. B 279, 1-510. doi: 10.1016/j.snb.2018.08.125

Wang, L., Zhang, J., Zhang, B., Liu, M., Fan, M., and Li, Q. (2018). "Experimental investigations on combustion behaviors of live PVC cables," in Materials Science Engineering Conference Series (Shanghai). doi: 10.1088/1757-899X/322/3/032004

Yi, J., Chen, W., Han, J., and Chen, D. (2019). Sensitive and selective detection of plasticizer vapors with modified- $\mathrm{SnO}_{2}$ hollow nanofibers for electrical fire warning. Sens. Actuat. B 287, 364-370. doi: 10.1016/j.snb.2019.02.025

Yi, J., Zhang, H., Zhang, Z., and Chen, D. (2018). Hierarchical porous hollow $\mathrm{SnO}_{2}$ nanofiber sensing electrode for high performance potentiometric $\mathrm{H}_{2}$ sensor. Sens. Actuat. B 268, 456-464. doi: 10.1016/j.snb.2018.04.086

Zhao, Y., Zhang, S., Zhang, G., Deng, X., and Xie, C. (2014). Highly sensitive porous metal oxide films for early detection of electrical fire: surface modification and high throughput screening. Sens. Actuat. B 191, 431-437. doi: 10.1016/j.snb.2013.09.111

Conflict of Interest: The authors declare that the research was conducted in the absence of any commercial or financial relationships that could be construed as a potential conflict of interest.

Copyright (c) 2019 Han, Chen, Yu and Yi. This is an open-access article distributed under the terms of the Creative Commons Attribution License (CC BY). The use, distribution or reproduction in other forums is permitted, provided the original author(s) and the copyright owner(s) are credited and that the original publication in this journal is cited, in accordance with accepted academic practice. No use, distribution or reproduction is permitted which does not comply with these terms. 